\title{
Coil End Parts Development Using BEND and Design for MQXF by LARP
}

\author{
M. Yu, G. Ambrosio, S. Izquierdo Bermudez, R. Bossert, J. Brandt, P. Ferracin, S. Krave
}

\begin{abstract}
End parts are critical components for saddle-shaped coils. They have a structural function where the cables are deformed in order to cross over the magnet aperture. Based on the previous design of the US LARP program for $90 \mathrm{~mm}$ aperture quadrupoles (TQ/LQ) and $120 \mathrm{~mm}$ aperture quadrupoles (HQ/LHQ) using BEND, the coil ends of the low- $\beta$ quadruples (MQXF) for the HiLumi LHC upgrade were developed. This paper shows the design of the MQXF coil ends, the analysis of the coil ends during the coil fabrication, the autopsy analysis of the coil ends and the feedback to BEND parameters.
\end{abstract}

Index Terms-BEND, Coil end, End parts, LARP, HiLumi LHC, MQXF

\section{INTRODUCTION}

L ARP, LHC Accelerator Research Program, has been focusing on the development of high-gradient $\mathrm{Nb}_{3} \mathrm{Sn}$ quadruples for future upgrades of the LHC since 2004 [1]. For the first four years, Technological Quadrupole (TQ) models, with $90 \mathrm{~mm}$ aperture, were designed, fabricated and tested successfully [2]. For the second four years starting from 2008, High-gradient Quadrupole (HQ) models, with $120 \mathrm{~mm}$ aperture, were designed, fabricated and tested successfully [3][4]. In 2012, it was decided to upgrade the inner triplet magnets in the current LHC IRs using $\mathrm{Nb}_{3} \mathrm{Sn}$ magnets with $150 \mathrm{~mm}$ aperture (MQXF) [5]-[6].

The coils of TQ, HQ and MQXF are all shell style. The keystoned-shape cable is wound on a cylindrical mandrel to produce a coil with the straight section and at the end the cable rises up, travels on top of the mandrel, drops down and continues the straight section at the opposite side. To design such a coil, firstly the 2D magnetic analysis of the straight section has to be done using ROXIE. Secondly the dimensional information of each cable turn in the coil crosssection is transferred to BEND for the optimization of the coil ends. BEND program was developed to minimize the strain energy in the coil end during SSC magnet design period [7]. During the optimization process, the longitudinal position of each conductor block in both coil ends also need to be tuned to minimize the peak field. After the optimization, the output

Work supported by the US Department of Energy through the US LHC Accelerator Research Program (LARP) and by the High Luminosity LHC project at CERN.

M. Yu, G. Ambrosio, R. Bossert, J. Brandt, and S. Krave are with Fermi National Laboratory (FNAL), IL 60510 USA (corresponding author to provide phone: 630-840-4539; fax: 630-840-3369; e-mail: miaoyu@fnal.gov).

S. Izquierdo Bermudez and P. Ferracin are with CERN, 1211 Geneva, Switzerland. files, containing the point clouds of each conductor block, are imported into CAD software for modeling the coil ends and the end parts.

This paper describes the parameters used by BEND for coil ends optimization. Subsequently it presents the design of the end parts for MQXF based on the end parts development performed for TQ and HQ coils. Lastly the feedback from coil winding and coil-end autopsy is presented. A good match between turns and end parts is expected, in order to reduce epoxy in the gaps (possible source of training) and to avoid insulation degradation during winding.

\section{PARAMETERS IN BEND}

After obtaining the 2D coil cross-section from the magnetic design, the flow chart of the coil end design using BEND is shown in Fig. 1. As the cable is wound from the straight section up to the nose of the coil end, the mid-thickness of the cable increases gradually, while the keystone angle decreases gradually. These changes are captured in BEND by defining as four cable-shape-change parameters, FAT1, FAT2, KEY1 and KEY2. FAT1 is defined as the mid-thickness increasing rate at the group midpoint, FAT2 is defined as the midthickness increasing rate at group termination or nose. KEY1 is defined as the keystone angle decreasing rate at the group midpoint, and KEY2 is defined as the keystone angle decreasing rate at the group termination or nose. These four parameters are hard coded inside BEND, which has to be changed before running BEND program.

The coil end is divided in conductor groups [8]-[10]. Each group has its boundaries, called inside surface and outside surface, as shown in Fig. 2(a). The guiding strip is defined as the least-strain surface, one for each group, as shown in Fig. 2(b). The number of conductors stacking on either side of guiding strip is specified by the user. Usually it is placed at the first conductor surface if the number of conductors in the group is no more than 15 .

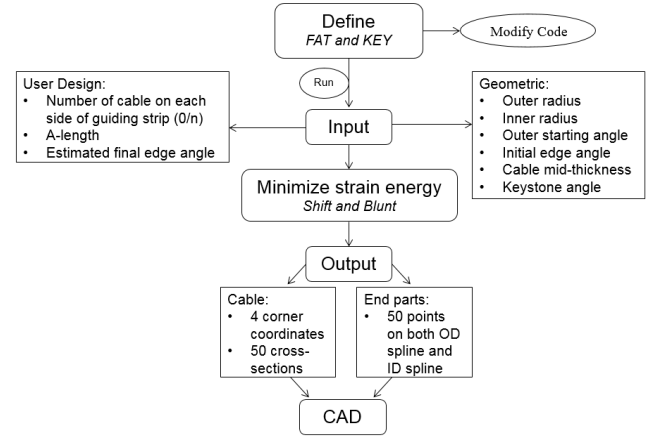

Fig. 1 Flow Chart for End Design using BEND 


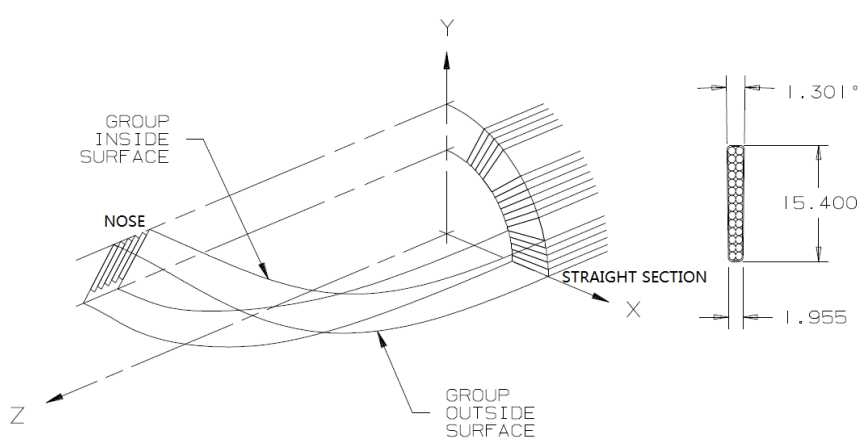

(a). Group Surfaces

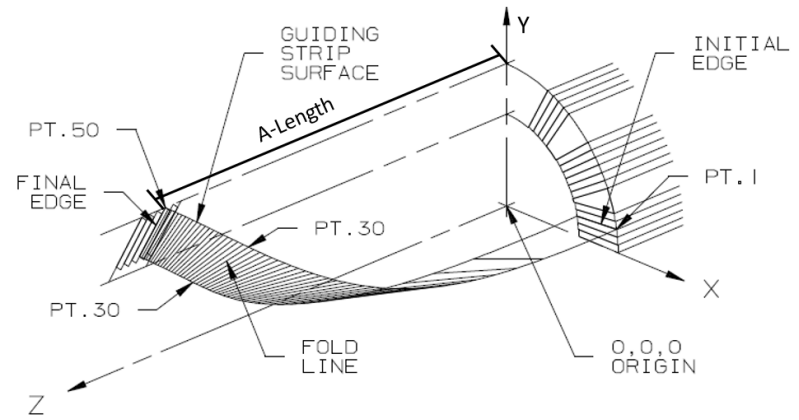

(b). Guiding Strip

Fig. 2 Coil End Group Surfaces

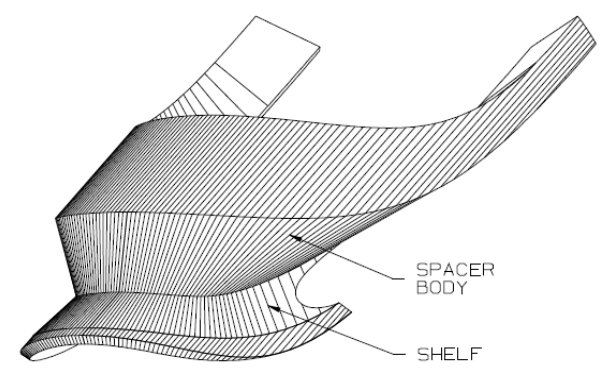

Fig. 3 End Part with Spacer Body and Shelf

A-length is the longitudinal distance of the cable, where the guiding strip locates at, travels along the OD surface at the coil end, as shown in Fig. 2(b). It is first determined by ROXIE 3D coil end magnetic analysis, and if the strain of the cable cannot be optimized in BEND, it requires the design iteration.

In Fig. 2(b), the edge of the guiding strip surface that lies in the $\mathrm{X}-\mathrm{Y}$ plane is called the initial edge, the edge that lies in the $\mathrm{Y}-\mathrm{Z}$ plane is called the final edge. The angles from vertical of these edges are called the initial edge angle and the final edge angle. The final edge angle is estimated by the user, the more conductors in the group, the larger the angle is required, however it is limited up to $25^{\circ}$, to avoid building the thin and sharp metal shelf on the part, see Fig. 3.

The angle from vertical of a line passing through the origin and through the intersection of the initial edge and the outer radius of either inner layer coil or outer layer coil is called the starting angle. This angle is determined from the geometry of the coil cross-section, as well as outer radius, inner radius and initial edge angle of either inner layer or out layer of the coil.

During the BEND optimization, there are two parameters, SHIFT $(-2,2)$ and BLUNT $(0,0.5)$, which can be adjusted to minimize the guiding strip strain.

\section{III. $1^{\text {st }}$ GenERATION MQXF COIL END DESIGN}

\section{A. HQ03 Coil End Analysis}

The design of MQXF magnet [11] is based on HQ magnet [12], by scaling up the bore diameter from $120 \mathrm{~mm}$ to 150 mm. HQ02 and HQ03 magnets were tested and performed very well. One of the HQ03 coils [13] was cut in the coil end, and autopsy analysis was done to study the cable-shapechange parameters to be used for MQXF coil end design. Fig. 4 shows the autopsy of the HQ coil return end, longitudinal cut 1 , dividing the coil end into halves to explore the coil end at the nose, and three oblique cuts to explore the coil end at the mid-point of the groups. Fig. 5 shows the cross-section view of the coil at longitudinal cut 1 with the CAD model design dimension, oblique cut 2 and oblique cut 3.

Observation of the three cross-sections shows that the edge of the end parts is pretty parallel to the edge of the cable group, so KEY1 and KEY2 of HQ coil are adopted for MQXF coil. For FAT2, it may be observed that at the nose in Fig.5 (a), the cable exceeds the expected group width by half of a turn. Therefore FAT2 is increased from 1.055 (for HQ coil) to 1.073 (for MQXF coil). In Fig.5 (a), a gap can be seen between the end part and the cable. This is because the end part is pressed against the cables at the group mid-point area, so that the end part cannot fit in position at the nose. Therefore FAT1 is increased from 1.045 to 1.091 .

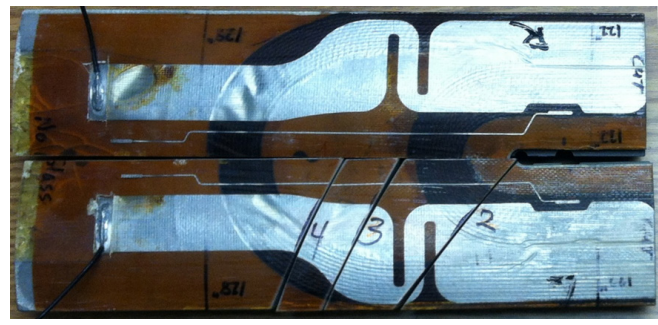

Fig. 4 HQ03 Coil Return End Autopsy

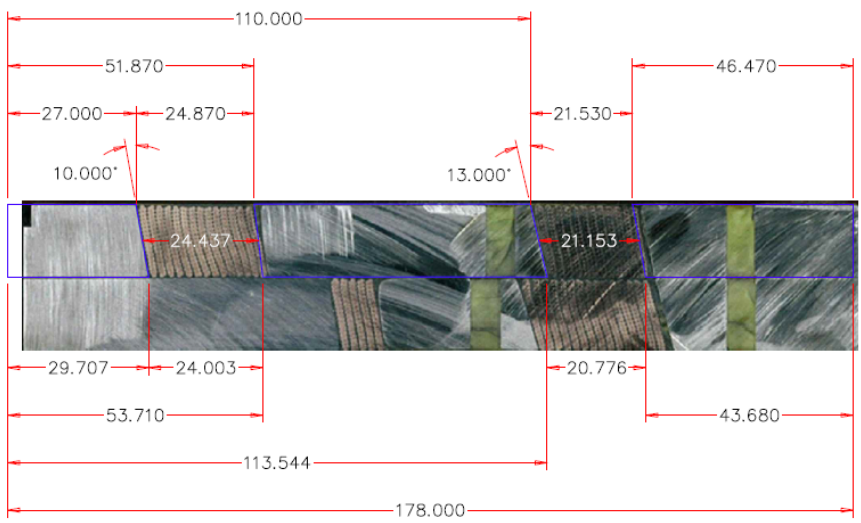

(a). Longitudinal Cut 1

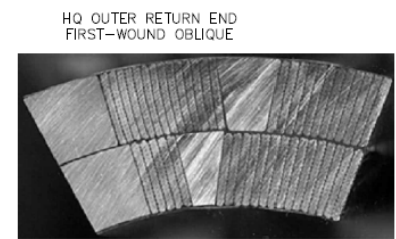

(b). Oblique Cut 2

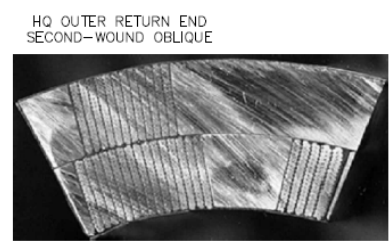

(c). Oblique Cut 3
Fig. 5 HQ Coil End Cross-sections 
TABLE 1 CABLE-SHAPE-CHANGE PARAMETERS

TABLE 2 BEND INPUT PARAMETERS for both $1^{\text {st }}$ and $2^{\text {nd }}$ Generation

\begin{tabular}{cccc}
\hline \hline PARAMETERS & HQ03 COIL & MQXF COIL & MQXF COIL \\
\hline Reacted Cable mid- & 1.575 & 1.894 & 1.884 \\
Keystone Angle & 0.75 & 0.55 & 0.4 \\
KEY1 & 0.6 & 0.6 & 0.6 \\
KEY2 & 0.3 & 0.3 & 0.3 \\
FAT1 & 1.045 & 1.091 & 1.091 \\
FAT2 & 1.055 & 1.073 & 1.073 \\
\hline
\end{tabular}

Table 1 summaries the cable-shape-change parameters. These parameters are hard coded into BEND program, and each conductor group can have its own parameters so that the optmization can be done independently from the other groups. At start point, the same parameters are used to design different groups for MQXF coil ends.

\section{B. MQXF Coil End Design}

The 2D magnetic design of MQXF $1^{\text {st }}$ generation coil was described in [14]. With the coil 2D cross section, see Fig. 6(a), coil center pole and wedges for both inner and outer layer of the coil were designed straightforwardly in CAD software.

3D magnetic analysis and the magnetic coil end design were performed at CERN using ROXIE. The resulting conductor groups are shown in Fig. 6(b). The major input parameters for MQXFA ends are listed in Table 2. Two design iterations $\left(1^{\text {st }}\right.$ and $2^{\text {nd }}$ generations) were performed and tested on prototypes. Each coil set includes two end pole pieces and eight end parts for each layer, as shown in Fig. 7.

The ends of MQXFB coils, fabricated at CERN, were designed using ROXIE. The ends of MQXFA coils fabricated by LARP were designed using BEND. Both designs performed very well in a short model test (MQXFS1), and can be exchanged as a set for future coil fabrication [15].

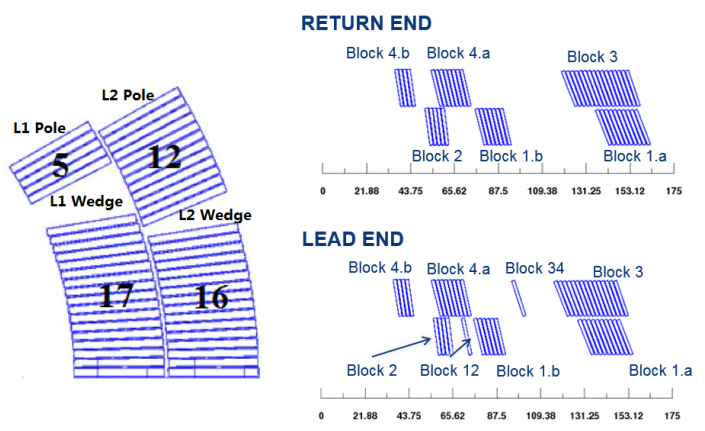

$\begin{array}{ll}\text { (a). } 2 \mathrm{D} \text { cross-section } & \text { (b). Conductor groups at coil ends }\end{array}$

Fig. $6 \mathrm{MQXF} 1^{\text {st }}$ Generation Coil Cross-section

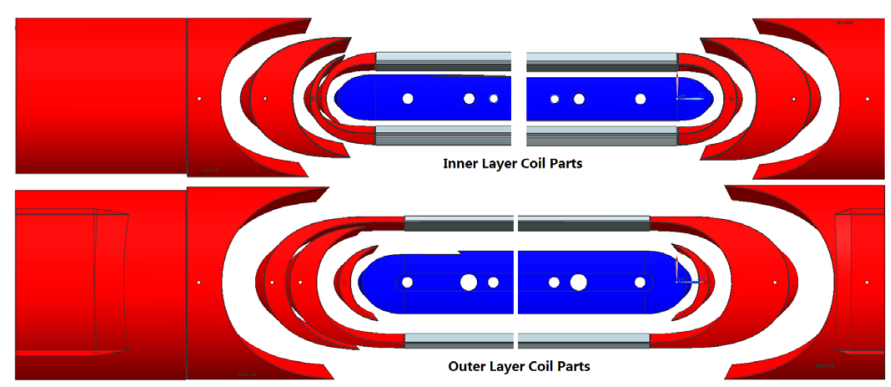

Fig. 7 MQXF $1^{\text {st }}$ Generation Coil Parts

\begin{tabular}{cccccc}
\hline & $\begin{array}{c}\text { Group } \\
\text { (Block \#) }\end{array}$ & $\begin{array}{c}\text { No. of } \\
\text { Conductors }\end{array}$ & $\begin{array}{c}\text { Conductors } \\
\text { on each side }\end{array}$ & $\begin{array}{c}\text { A-Length } \\
(\mathbf{m m}) \\
\left(\mathbf{1}^{\text {st }} / \mathbf{2}^{\text {nd }}\right)\end{array}$ & $\begin{array}{c}\text { Final Edge } \\
\text { Angle } \\
\left(\mathbf{1}^{\text {st }} / \mathbf{2}^{\text {nd }}\right)\end{array}$ \\
\hline & $1 \mathrm{a}$ & 10 & $0 / 10$ & $(71 / 71)$ & $(25 / 25)$ \\
$\mathrm{R}$ & $1 \mathrm{~b}$ & 7 & $0 / 7$ & $(49 / 49)$ & $(20 / 20)$ \\
$\mathrm{E}$ & 3 & 5 & $0 / 5$ & $(27 / 27)$ & $(9 / 9)$ \\
& 3 & 16 & $1 / 15$ & $(83 / 83)$ & $(22.5 / 22.5)$ \\
& $4 \mathrm{a}$ & 8 & $0 / 8$ & $(49 / 49)$ & $(14 / 14)$ \\
& $4 \mathrm{~b}$ & 4 & $0 / 4$ & $(35 / 35)$ & $(11 / 11)$ \\
\hline \hline & $1 \mathrm{a}$ & 10 & $0 / 10$ & $(78 / 78)$ & $(23.5 / 23.5)$ \\
& $1 \mathrm{~b}$ & 6 & $0 / 6$ & $(54 / 54)$ & $(20 / 20)$ \\
$\mathrm{L}$ & $1-2$ & 1 & $0 / 1$ & $(45 / 45)$ & $(13 / 13)$ \\
$\mathrm{E}$ & 2 & 4 & $0 / 4$ & $(31 / 31)$ & $(10 / 10)$ \\
& 3 & 15 & $0 / 15$ & $(94 / 94)$ & $(22 / 22)$ \\
& $3-4$ & 1 & $0 / 1$ & $(94 / 89)$ & $(19 / 19)$ \\
& $4 \mathrm{a}$ & 8 & $0 / 8$ & $(54 / 53)$ & $(13 / 13)$ \\
& $4 \mathrm{~b}$ & 4 & $0 / 4$ & $(35 / 35)$ & $(10 / 10)$ \\
\hline \hline
\end{tabular}

C. New Features on End Parts

End parts are designed based on the nominal coil size after coil reaction. During winding, however, the coil is not fully constrained on the winding mandrel and this effect is most pronounced at the coil ends. The cable separates from the radial surface of the mandrel, causing the shape of the turn to not match the shape of the end parts. This spring-back effect is larger with larger coil aperture and cable size, and it becomes more difficult to install the end parts without removing more material from the tips of the end parts. Fig. 8 shows the HQ coil end parts before and after removing some material to fit in the coil end. Therefore new flexible features, ("accordion slits"), have been introduced to the end parts, as shown in Fig. 9. With these features, the end parts can be opened up and installed during winding. After curing the coil is fully compressed to its nominal shape and the slits are closed accordingly. After impregnation, the epoxy that has filled the slits makes the end parts solid. The last end part in the coil end, due to the large coil end load, at LARP, it is replaced by a solid piece after coil curing. Whereas at CERN the slit parts are kept. After obtaining more magnet test results, it will be determined which procedure is better for production.

In order to increase the dielectric strength between the metal part and the cable, 0.01 " thick (with $+0,-0.002$ " tolerance) plasma coating has also been applied to the end parts. The coating material is $\mathrm{Al}_{2} \mathrm{O}_{3}$ powder.
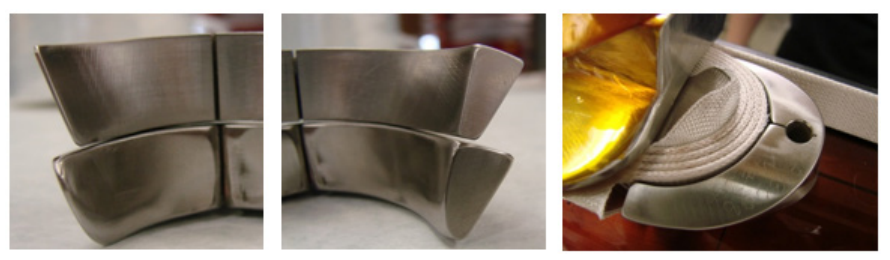

Fig. 8 HQ Coil End Part

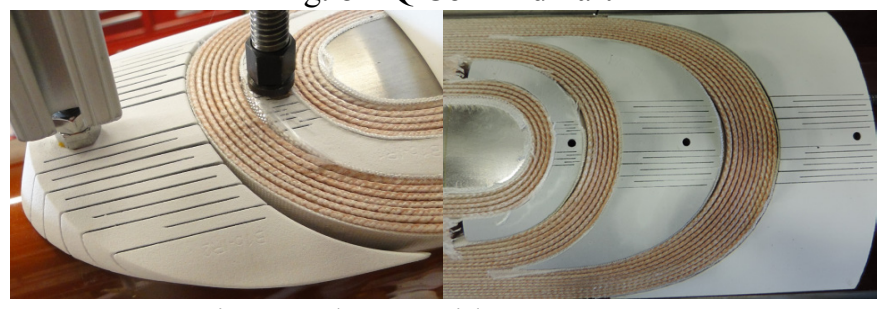

Fig. 9 End Parts with New Features 


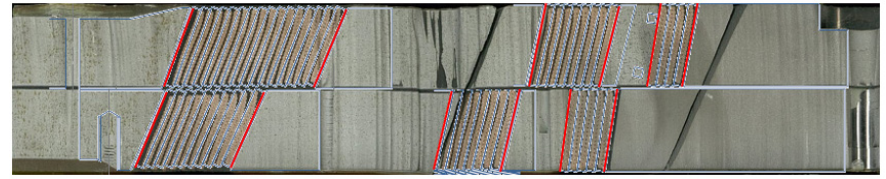

(a) Longitudinal Cut

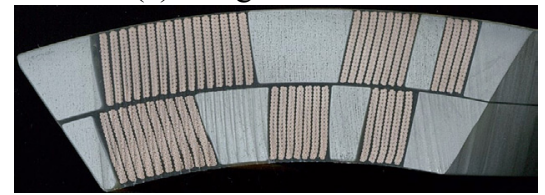

(b) Oblique Cut

Fig. 10 MQXF Coil End Cross-sections

\section{Coil End Autopsy Inspection}

A $1^{\text {st }}$ generation MQXF coil was fabricated and cut at both coil ends. Fig. 10(a) shows the cross-section at longitudinal cut of the coil return end, and Fig. 10(b) shows the crosssection at an oblique cut. The angle of the end parts is parallel to the angle of the cable layout, so KEY1 and KEY2 were well determined. In Fig. 10(a), the first conductor groups for both the inner layer and the outer layer are within the expected group width. The second conductor groups for both layers exceed the expected group width by about one third of a turn, however due to the flexible end parts, there is no gap between the cable and the part. The last conductor groups for both layers exceed the expected group width by about half of a turn. Since the flexible part after this conductor gourp was replaced by the solid one for the consideration of high coil end load, the remaining gap was filled with S2-glass fabric.

\section{IV. $2^{\mathrm{ND}}$ GENERATION MQXF COIL END DESIGN}

In order to limit the current degradation during cabling, the cable geometry was changed: the keystone angle was reduced from $0.55^{\circ}$ to $0.4^{\circ}$, and the mid-thickness from $1.894 \mathrm{~mm}$ to $1.884 \mathrm{~mm}$. The 2D and 3D coil magnetic design was updated [16]. With the new cross-section and coil end, see Fig. 11, the coil ends were redesigned, using the same cable-shape-change parameters shown in Table 1, and the input parameters shown in Table 2. Fig. 12 shows the $2^{\text {nd }}$ generation MQXF coil after curing. The end parts were easily installed and well fit in the coil end. Autopsy of the coil end will be studied after the coil is tested.

\section{CONCLUSION}

The MQXF coil end design, based on the coil end development performed by LARP using BEND, was described in this paper. The cable-shape-change parameters for MQXF coil were determined after the autopsy analysis on HQ coil ends. MQXFS01 magnet, consisting of four $1^{\text {st }}$ generation coils was successfully tested demonstrating the validity of the coil design. The $2^{\text {nd }}$ generation coil end design adopted the parameters of the $1^{\text {st }}$ generation, and five coils have been wound with well fit end parts. A series of prototype coils will be fabricated and tested in the coming two years, phasing into the coil production for HiLumi LHC accelerator upgrade project in FY18.

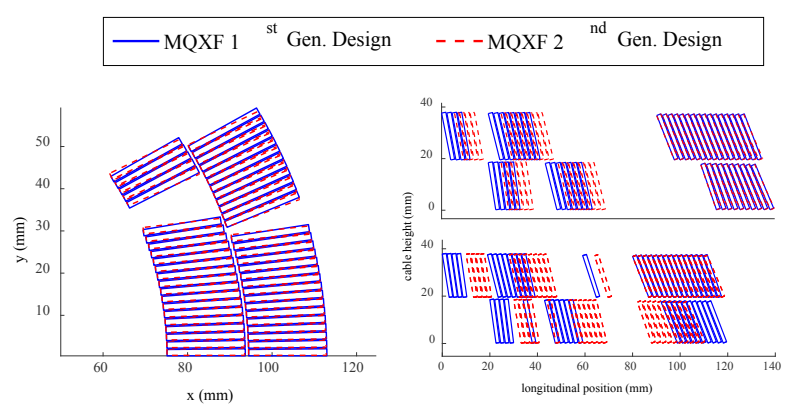

Fig. $112^{\text {nd }}$ Generation Coil Magnetic Design

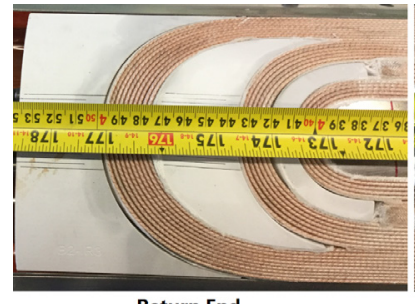

Return End

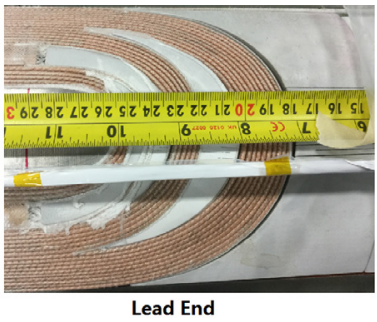

Lead End
Fig. $112^{\text {nd }}$ Generation Coil End after Curing

\section{REFERENCES}

[1] S. A. Gourlay, et al. "Magnet R\&D for the US LHC accelerator research program,” IEEE Trans. Appl. Supercond., vol. 16, no. 2, pp. 324-327, Jun. 2006.

[2] P. Ferracin, "LARP Nb3Sn quadrupole magnets for the LHC luminosity upgrade," in Proc. AIP Conf., 2010, vol. 1218, pp. 1291-1300.

[3] H. Felice, et al. "Design of HQ-A high field large bore Nb3Snquadrupole magnet for LARP," IEEE Trans. Appl. Supercond., vol. 19, no. 3, pp. 1235-1238, Jun. 2009.

[4] J. DiMarco, et al. "Test Results of the LARP Nb3Sn Quadrupole HQ03a”, IEEE Trans. Appl. Supercond., vol. 26, no. 4, Jun. 2016

[5] E. Todesco et al., "Design studies for the low-beta quadrupoles for the LHC luminosity upgrade," IEEE Trans. Appl. Supercond., vol. 23, no. 3, Jun. 2013, Art. ID 4002405.

[6] E. Todesco et al., "A first baseline for the magnets in the high luminosity LHC insertion regions," IEEE Trans. Appl. Supercond., vol. 24, no. 3, Jun. 2014, Art. ID 4003305.

[7] J.M. Cook, "Strain energy minimization in SSC magnet winding", IEEE Transaction on.Magnetics, vol. 27, no. 2, pp. 1976-1980, Mar., 1991.

[8] J. Brandt, et al., "Coil end design for the SSC collider dipole magnet", Conf.Proc. PAC 1991, C910506, pp. 2182-2184.

[9] J. Brandt, "Coil end design for the LHC dipole magnet", FERMILABTM-1954, May, 1996.

[10] J. Brandt, "Coil end parts design procedure", FERMILAB-TD-98-053, Sep., 1998.

[11] P. Ferracin, et al., "Magnet Design of the $150 \mathrm{~mm}$ Aperture Low- $\beta$ Quadrupoles for the High Luminosity LHC", IEEE TRANSACTIONS ON APPLIED SUPERCONDUCTIVITY, vol. 24, no. 3, Jun. 2014. Art. ID 4002306.

[12] H. Felice, et al., "Design of HQ-A high field large bore Nb3Snquadrupole magnet for LARP”, IEEE Trans. Appl. Supercond., vol. 19, no. 3, pp. 1235-11239, Jun. 2009.

[13] F. Borgnolutti, et al., "Fabrication of a Third Generation of Nb3Sn Coils for the LARP HQ03 Quadrupole Magnet", IEEE TRANSACTIONS ON APPLIED SUPERCONDUCTIVITY, VOL. 25, NO. 3, JUNE 2015, Art. ID 4002505.

[14] F. Borgnolutti et al., "Magnetic design optimization of a $150 \mathrm{~mm}$ aperture Nb3Sn low-beta quadrupole for the HiLumi LHC," IEEE Trans. Appl. Supercond., vol. 24, no. 3, Jun. 2014, Art. ID 4000405.

[15] S. Izquierdo Bermudez, et al., "Coil End Optimization of the $\mathrm{Nb}_{3} \mathrm{Sn}$ Quadrupole for the High Luminosity LHC", IEEE TRANSACTIONS ON APPLIED SUPERCONDUCTIVITY, VOL. 25, NO. 3, JUNE 2015, Art. ID 4001504.

[16] S. Izquierdo Bermudez, et al., "Second Generation Coil Design of the Nb3Sn low- $\beta$ Quadrupole for the High Luminosity LHC", IEEE Transactions on Applied Superconductivity. 26 (2016) no.4, 4001105 